\title{
Maternal near miss events: a prospective observational study in a tertiary care centre
}

\author{
Gazala Yasmin $^{1}$, Rehana Najam ${ }^{1}$, Shahreyar Ghazi ${ }^{2}$, Astha Lalwani ${ }^{1}$ \\ ${ }^{1}$ Department of Obstetrics and Gynaecology, ${ }^{2}$ Department of Emergency Medicine, TMMC and RC, Moradabad, Uttar
} Pradesh, India

Received: 12 July 2016

Accepted: 05 August 2016

*Correspondence:

Dr. Gazala Yasmin,

E-mail: dr.gazala_yasmin@yahoo.co.in

Copyright: ( ) the author(s), publisher and licensee Medip Academy. This is an open-access article distributed under the terms of the Creative Commons Attribution Non-Commercial License, which permits unrestricted non-commercial use, distribution, and reproduction in any medium, provided the original work is properly cited.

\begin{abstract}
Background: A maternal near miss case is defined as a woman who nearly died but survived a complication that occurred during pregnancy, childbirth or within 42 days of termination of pregnancy. In 2009, World Health Organization (WHO) has developed new system based on organ system dysfunction which incorporates clinical, laboratory and management based criteria for identifying maternal near miss. Fortunately, most of the obstetrical complications can be prevented or managed provided a timely and proper intervention is taken. Hence, this study was conducted with the objectives to determine the frequency, to study the demographic characteristics, causes, interventions and feto- maternal outcome of the maternal near miss cases.

Methods: A prospective observational study was conducted in Teerthanker Mahaveer Medical College and research Centre, Moradabad, Uttar Pradesh from July 2015 to June 2016. All patients according to WHO inclusion criteria for maternal near miss were included in the study. All relevant data were collected on the pre-designed proforma in details regarding age, parity, gestational age, causes, interventions taken, feto-maternal outcome.

Results: Total number of near miss cases were 122, maternal near- miss incidence ratio was 45.2 per 1000 live births. Most of the cases of maternal near- miss in this study were in the age group of 20-35 years (71.3\%), multipara (61.5), in the third trimester. Most common cause for maternal near- miss in the present study was found to be hemorrhage (44.3\%) followed by hypertensive disorders of pregnancy (HDP) $34.4 \%$ followed by dystocia (14.8\%), sepsis (2.4\%) and anemia $(4.1 \%)$. Neurological dysfunction $(10.7 \%)$ was the most common organ dysfunction. Nearly $42.6 \%$ nearmiss admissions were delivered by LSCS, $48.4 \%$ were live births and $28.7 \%$ were still births.

Conclusions: This study concludes hemorrhage and hypertensive disorders to be the leading causes for maternal near miss. Hence evaluation of the circumstances surrounding near-miss can give us an idea to know the exact etiology, treat it in its early stage and prevent death.
\end{abstract}

Keywords: Maternal near miss, Prospective observational study, WHO criteria, Sociodemographic characteristics, Feto-maternal outcome

\section{INTRODUCTION}

A maternal death is one of the most devastating events in obstetrics with widespread implications on both the family and the medical staff involved. Every woman goes through a risk for this sudden and unexpected event during pregnancy, childbirth and after delivery. A maternal near miss case is defined as a woman who nearly died but survived a complication that occurred during pregnancy, childbirth or within 42 days of termination of pregnancy. ${ }^{1}$ In practical terms, women are considered near-miss cases when they survive lifethreatening conditions. Fortunately, most of the obstetrical complications can be prevented or managed provided a timely and proper intervention is taken.

The advantage of evaluating the near miss cases is that these events are more frequent and hence, comprehensive 
and reliable information can be drawn and rapid audits can be conducted. ${ }^{2-5}$ Near- miss cases share many characteristics with maternal death and can directly inform on obstacles that had to overcome after the onset of an acute complication. At the same time, the survivor herself can be a source of information. As surviving a near miss event mainly occurs because of the care provided, inquiring into the events of near miss would boost up the morale of the care providers. Usually, near miss morbidity precedes maternal death. Therefore, identifying and analysing the cases of maternal near miss helps in understanding the factors that determine maternal mortality. 6,7

There are many ways of identifying maternal near miss cases using various sets of criteria like disease specific, management specific and organ system dysfunction based. Amongst these, organ system dysfunction based criteria have been noted to be epidemiologically sound and less affected by bias in identifying maternal near miss cases. ${ }^{8}$ In 2009, World Health Organization (WHO) has developed new system based on organ system dysfunction which incorporates clinical, laboratory and management based criteria for identifying maternal near miss. $^{4}$ It has been then recommended that WHO near miss approach for maternal death be uniformly used in analysing the cases of near miss maternal mortality. ${ }^{1}$ It includes the following:

\section{Severe maternal complications}

- Severe postpartum haemorrhage

- Severe pre-eclampsia

- Eclampsia

- Sepsis or severe systemic infection

- Ruptured uterus

- Severe complications of abortion

\section{Critical interventions or intensive care unit use}

- Admission to intensive care unit

- Interventional radiology

- Laparotomy (includes hysterectomy, excludes caesarean section)

- Use of blood products

\section{Life-threatening conditions (near-miss criteria)}

- Cardiovascular dysfunction - shock, cardiac arrest (absence of pulse/ heart beat and loss of consciousness), use of continuous vasoactive drugs, cardiopulmonary resuscitation, severe hypo perfusion (lactate $>5 \mathrm{mmol} / \mathrm{l}$ or $>45 \mathrm{mg} / \mathrm{dl}$ ), severe acidosis $(\mathrm{pH}<7.1)$.

- Respiratory dysfunction - acute cyanosis, gasping, severe tachypnea (respiratory rate $>40$ breaths per minute), severe bradypnea (respiratory rate $<6$ breaths per minute), intubation and ventilation not related to anaesthesia, severe hypoxemia $(\mathrm{O} 2$ saturation $<90 \%$ for $\geq 60$ minutes or $\mathrm{PAO} 2 / \mathrm{FiO} 2$ $<200$ )

- Renal dysfunction - oliguria nonresponsive to fluids or diuretics, dialysis for acute renal failure, severe acute azotemia (creatinine $\geq 300 \mu \mathrm{mol} / \mathrm{ml}$ or $\geq 3.5$ $\mathrm{mg} / \mathrm{dl}$ )

- Coagulation/haematological dysfunction - failure to form clots, massive transfusion of blood or red cells ( $\geq 5$ units), severe acute thrombocytopenia $(<50000$ platelets/ml)

- Hepatic dysfunction - jaundice in the presence of pre-eclampsia, severe acute hyperbilirubinemia (bilirubin $>100 \mu \mathrm{mol} / \mathrm{l}$ or $>6.0 \mathrm{mg} / \mathrm{dl}$ )

- Neurological dysfunction - prolonged unconsciousness (lasting $\geq 12$ hours)/coma (including metabolic coma), stroke, uncontrollable fits/status epilepticus, total paralysis

- Uterine dysfunction - uterine haemorrhage or infection leading to hysterectomy.

The objective of this study was to determine the frequency of maternal near miss events. And to study the sociodemographic characteristics of the near miss cases. To analyse the causes of near miss events, to know the interventions taken to treat the patients to evaluate the feto-maternal outcome of the near miss cases in the study.

\section{METHODS}

It is a prospective observational study conducted in the department of obstetrics and gynaecology, Teerthanker Mahaveer Medical College and Research Centre, Moradabad, Uttar Pradesh, India. Ours is a tertiary care institute, it is a referral hospital for both public and private hospitals in Moradabad and other surrounding districts in Uttar Pradesh. In addition to providing twenty-four-hour emergency obstetric services, the hospital also provides antenatal care and delivery services for both low and high risk pregnant women. Hospital has 24-hour facility for blood component therapy. High dependency unit (HDU) in labor room complex and intensive care ICU with 24-hour facility for multidisciplinary specialty also function well.

Any patient who met the WHO inclusion criteria for maternal near- miss mortality, mentioned above, during the period July 2015 to June 2016 was included in study.

Data have been collected from the patients having Near Miss Mortality event during the hospital stay on a predesigned a proforma prepared for the study. Patient characteristics including age, parity, gestational age at admission, type of admission, booking status and interventions taken to save the life of the patient were also noted.

Investigations were done for anemia, septicemia, eclampsia and for organ system dysfunction/ failure. Data was collected for determining the nature of obstetric 
complication, presence of organ system dysfunction and timing of near miss events with respect to admission.

Mode of delivery and the fetal outcome was also noted.

\section{RESULTS}

There were 2817 deliveries and 2697 live births during the study period. Total number of near miss cases was 122. Maternal near miss incidence ratio obtained in the present study is 45.2 per 1000 live births.

Table 1: Demographic characteristics of near miss cases in the study.

\begin{tabular}{|c|c|c|c|}
\hline \multicolumn{2}{|c|}{ Characteristic } & $\begin{array}{l}\text { Number } \\
(\mathrm{n}=122)\end{array}$ & $\begin{array}{l}\text { Percentage } \\
(\%)\end{array}$ \\
\hline \multirow{3}{*}{ Age } & $<20$ years & 24 & 19.7 \\
\hline & 20-35 years & 87 & 71.3 \\
\hline & $>35$ years & 11 & 9.0 \\
\hline \multirow{2}{*}{ Parity } & Primi & 47 & 38.5 \\
\hline & Multi & 75 & 61.5 \\
\hline \multirow{2}{*}{ ANC care } & Yes & 02 & 1.6 \\
\hline & No & 120 & 98.4 \\
\hline \multirow{4}{*}{$\begin{array}{l}\text { Gestational } \\
\text { age }\end{array}$} & $<13$ weeks & 26 & 21.3 \\
\hline & 13-28 weeks & 09 & 7.4 \\
\hline & $>28$ weeks & 64 & 52.5 \\
\hline & Postpartum & 23 & 18.8 \\
\hline \multirow{2}{*}{$\begin{array}{l}\text { Type of } \\
\text { admission }\end{array}$} & Self & 54 & 44.3 \\
\hline & Referred & 68 & 55.7 \\
\hline \multirow{2}{*}{ Near miss } & On admission & 120 & 98.4 \\
\hline & After admissior & r 02 & 1.6 \\
\hline \multicolumn{2}{|c|}{ Total of each characteristics } & 122 & 100 \\
\hline
\end{tabular}

Table 2: Causes of near miss events in the study.

\begin{tabular}{|lll|}
\hline Causes & $\begin{array}{c}\text { Number } \\
(\mathbf{n = 1 2 2})\end{array}$ & $\begin{array}{l}\text { Percentage } \\
(\%)\end{array}$ \\
\hline Hypertensive disorders & & \\
\hline Severe pre - eclampsia & 12 & 9.8 \\
\hline Eclampsia & 30 & 24.6 \\
\hline Severe haemorrhage & & \\
\hline Early pregnancy & & \\
\hline Ectopic & 19 & 15.6 \\
\hline Abortion & 07 & 5.7 \\
\hline Late pregnancy & & \\
\hline APH & 12 & 9.8 \\
\hline PPH & 16 & 13.2 \\
\hline Sepsis & & \\
\hline Puerperal sepsis & 02 & 1.6 \\
\hline Chorioamnionitis & 01 & 0.8 \\
\hline Dystocia & & \\
\hline Uterine rupture & 16 & 13.2 \\
\hline Impending rupture & 02 & 1.6 \\
\hline Anemia & 05 & 4.1 \\
\hline Total & $\mathbf{1 2 2}$ & $\mathbf{1 0 0}$ \\
\hline
\end{tabular}

Table 1 shows the demographic characteristics of the near miss cases in the present study. The most common age group affected in the near miss cases in the present study was 20 to 35 years $(71.3 \%)$. While 47 cases $(38.5 \%)$ were primipara; $75(61.5 \%)$ cases were multipara. Maximum cases had not received any ANC care (98.4\%). Majority of the cases, i.e. 87 cases out of which 64 were in the third trimester and 23 in the postpartum period indicating that late pregnancy and delivery is the worst affected period. There were $55.7 \%$ referred case; on the other hand $44.3 \%$ were self-admissions. While $98.4 \%$ cases were near miss at the time of admission itself, only $1.6 \%$ became near miss cases after admission in our hospital.

The most common cause of near miss events in the present study (Table 2) was hemorrhage- 54 cases $(44.3 \%)$, followed by hypertensive disorders of pregnancy- 42 cases $(34.4 \%)$ and dystocia- 18 cases $(14.8 \%)$. Other causes were sepsis- 3 cases $(2.4 \%)$ and severe anemia (non-hemorrhagic) - 5 cases $(4.1 \%)$.

Table 3: Organ system dysfunction in near miss cases in the study.

\begin{tabular}{|ll|l|}
\hline Organ dysfunction & $\begin{array}{l}\text { Number } \\
(\mathbf{n}=122)\end{array}$ & Percentage (\%) \\
\hline Neurological & 13 & 10.7 \\
\hline Respiratory & 05 & 4.1 \\
\hline Cardiac & 04 & 3.3 \\
\hline Hematological & 12 & 9.8 \\
\hline Coagulation & 10 & 8.2 \\
\hline Hepatic & 05 & 4.1 \\
\hline Renal & 08 & 6.6 \\
\hline Uterine & 07 & 5.7 \\
\hline
\end{tabular}

12 women had more one system involvement.

Amongst the near miss cases in the present study the most common organ system dysfunction (Table 3) was neurological dysfunction $(10.7 \%)$, most of them were in cases of eclampsia. Other organ dysfunctions were hematological $(9.8 \%)$, coagulation dysfunction $(8.2 \%)$, renal dysfunction $(6.6 \%)$, uterine dysfunction leading to hysterectomy in 7 cases $(5.7 \%)$, hepatic and respiratory dysfunction $(4.1 \%$ each) and cardiovascular dysfunction $(3.3 \%)$.

Table 4 shows the properly timed interventions that were secured to the near miss patients which saved their lives. Most of them needed ICU admission (75.4\%). Blood and blood products transfusions were needed in $42.6 \%$. Magnesium sulphate therapy was given in 40 cases; they were all cases of eclampsia or severe pre-eclampsia. Laprotomy for either rupture uterus or ruptured ectopic were done in $31.1 \%$. Another $31.1 \%$ needed ventilatory support. Ionotrope support was needed in $15.6 \%$. Hysterectomy was done in 7 cases. Many near miss patients needed more than one intervention during their management. 
Table 4: Interventions needed in the management of near miss cases in the study.

\begin{tabular}{|lll|}
\hline Intervention & $\begin{array}{l}\text { Number } \\
(\mathbf{n}=\mathbf{1 2 2})\end{array}$ & $\begin{array}{l}\text { Percentage } \\
(\%)\end{array}$ \\
\hline Laprotomy & 38 & 31.1 \\
\hline $\begin{array}{l}\text { Massive blood and blood } \\
\text { products transfusion }\end{array}$ & 52 & 42.6 \\
\hline Higher antibiotic use & 24 & 19.7 \\
\hline Hysterectomy & 7 & 5.7 \\
\hline Inotrope support & 19 & 15.6 \\
\hline Mechanical ventilation & 38 & 31.1 \\
\hline ICU admission & 92 & 75.4 \\
\hline Magnesium sulphate therapy & 40 & 32.8 \\
\hline
\end{tabular}

Table 5: Mode of delivery of near miss cases in the study.

\begin{tabular}{|lll|}
\hline Mode of delivery & $\begin{array}{l}\text { Number } \\
(\mathbf{n = 1 2 2})\end{array}$ & $\begin{array}{l}\text { Percentage } \\
(\%)\end{array}$ \\
\hline Vaginal & 28 & 23 \\
\hline Caesarean section & 52 & 42.6 \\
\hline $\begin{array}{l}\text { Laparotomy for rupture } \\
\text { uterus }\end{array}$ & 16 & 13.1 \\
\hline Laparotomy for ectopic & 19 & 15.6 \\
\hline Dilatation and evacuation & 07 & 5.7 \\
\hline Total & $\mathbf{1 2 2}$ & $\mathbf{1 0 0}$ \\
\hline
\end{tabular}

Table 6: Neonatal Outcome of the near miss cases in the study.

\begin{tabular}{|lll|}
\hline Neonatal outcome & $\begin{array}{l}\text { Number } \\
(\mathbf{n}=122)\end{array}$ & $\begin{array}{l}\text { Percentage } \\
(\%)\end{array}$ \\
\hline Live births & 59 & 48.4 \\
\hline Healthy & 33 & \\
\hline LBW & 07 & \\
\hline Birth asphyxia & 19 & \\
\hline Still birth & 35 & 28.7 \\
\hline $\begin{array}{l}\text { First trimester termination } \\
\text { (abortion and ectopic) }\end{array}$ & 28 & 22.9 \\
\hline Total & $\mathbf{1 2 2}$ & $\mathbf{1 0 0}$ \\
\hline
\end{tabular}

The result of the mode of delivery is depicted in Table 5, $42.6 \%$ delivered by LCSC, while $23 \%$ were delivered normally.

Regarding neonatal outcome 59 cases had live births, out of which 33 were healthy babies, 7 were low birth weight, 19 had birth asphyxia. While 35 cases had still births.

\section{DISCUSSION}

Maternal near miss incidence ratio in the present study is 45.2 per 1000 live births, which is similar to the study conducted in Assam 42.1/1000 live births, Nepal 40/ 1000 live births and Karachi 50.6/1000 live births. ${ }^{9-11}$ On the other hand it was much less $17.8 / 1000$ in a study by
Roopa PS et al from Karnataka. ${ }^{12}$ In other studies the ratio was 32.9/1000 live births and 23.6/1000 live births. $^{13,14}$

Most of the cases of maternal near miss in this study were in the age group of 20-35 years $(71.3 \%)$ which is similar to the other studies conducted in Ethiopia and Nepal. ${ }^{10,15}$

In our study majority of the women becoming near miss were multipara $(61.5 \%)$ which is supported by other studies. ${ }^{10,16,17}$ Third trimester was the worst time for the pregnant women to land up in life threatening situations as in the present study and other studies..$^{10,15}$

Near miss events are mainly due to not availing any antenatal care, which indirectly is due to lack of knowledge amongst the pregnant women about it. This fact is supported by the present study in which $98.4 \%$ had not taken any antenatal care, and by other studies conducted in various parts of the world. ${ }^{10,11,18-20}$

Majority of the cases were referred to our hospital from other public or private hospitals (55.7\%) as was the case in other studies. ${ }^{15,19,20}$ And these were near- miss events on admission (98.4\%) itself rather than becoming nearmiss after admission to our hospital, which is consistent with other studies. ${ }^{10,13,15,19,20}$

The most common cause for maternal near - miss in the present study was found to be hemorrhage (44.3\%) followed by hypertensive disorders of pregnancy (HDP) $34.4 \%$ followed by dystocia $(14.8 \%)$, sepsis $(2.4 \%)$ and anemia $(4.1 \%)$. Few African studies also shows similar results. ${ }^{13,19,21}$ Similar to our study Hemorrhage was the most common cause for near miss mortality in studies from Assam and Karachi and HDP was the second most common cause in various studies..$^{9,11,22-25}$ In contrast to our study, a study conducted in Syria showed HDP (52\%) to be the most common cause followed by hemorrhage and a study in Ethiopia concluded obstructed labour (45\%) to be the most predominant cause followed by hemorrhage. ${ }^{13,15}$ The African studies also revealed infections to be amongst the common causes for nearmiss along with hemorrhage, while in the present study infections were amongst the rare causes for near miss. $^{13,19,21}$

Regarding organ dysfunction neurological dysfunction $(10.7 \%)$ was the most common, seen especially in patients with eclampsia followed by hematological dysfunction (9.8\%). Other organ involvements were coagulation defect $(8.2 \%)$, renal dysfunction (6.6\%). In contrast to our study, various studies from Nepal, Karachi and Syria concluded hematological dysfunction to be the most predominant followed by neurological involvement. ${ }^{10,11,13,26,27}$

ICU admissions were needed in $75.4 \%$ of our near- miss patients which is similar to a study in Nepal, whereas in a study in Damascus, only $27 \%$ needed ICU admissions. ${ }^{10}$ 
Massive blood transfusion was needed in $42.6 \%$ of patients which were similar to few studies10, and differing from other studies. ${ }^{15}$ Laprotomy was needed to save the life of the patients in $31.1 \%$, whereas another study showed its need only in 5\%. ${ }^{10}$ Hysterectomy was done in 7 cases in our study, whereas it was done in 4 and 43 cases respectively in other studies. ${ }^{10,13}$

Nearly $42.6 \%$ near miss admissions were delivered by LSCS and $23 \%$ delivered by vaginal route in the present study. Similar results were obtained in other studies while in an Ethiopian study most of them delivered by vaginal route $(61 \%)$ and only $13 \%$ delivered by LSCS. ${ }^{10,13,15}$

Around $48.4 \%$ of the babies were live births and $28.7 \%$ were still births in our study which is similar to a study in Nepal10 while in other studies still births were much lower (6-9.4\%) and live births were more (82-90\%). ${ }^{13,15}$

\section{CONCLUSION}

In the present study there were 122 cases of maternal near miss and maternal near miss ratio was 45.2/1000 live births. This study concludes haemorrhage and hypertensive disorders to be the leading causes for the same. Hence, evaluation of the circumstances surrounding near miss can give us an idea to know the exact etiology, treat it in its early stage and prevent death. It can be done by proper and efficient management of haemorrhage, hypertensive disorders and anemia.

Proper training of the health care personnel, even at primary level, to handle these life threatening events and timely referral to a higher centre whenever necessary is very important in preventing maternal death. Also creating awareness among the women regarding the importance of routine antenatal check-up is quintessential.

\section{ACKNOWLEDGEMENTS}

The authors wish to thank the department of obstetrics and gynaecology of TMMC and RC, Moradabad to make this project happen. We wish to express our gratitude to Khushnaz Akbar, Junior Resident in our department, who took keen interest in filling the proforma for the study and helping in data collection.

\section{Funding: No funding sources}

Conflict of interest: None declared

Ethical approval: The study was approved by the Institutional Ethics Committee

\section{REFERENCES}

1. World Health Organization. Evaluating the quality of care for severe pregnancy complications - the WHO near- miss approach for maternal health. Geneva: World Health Organization; 2011.
2. Ronsman C, Fillipi V. Reviewing severe maternal morbidity: learning from survivors from life threatening complications: reviewing deaths and complications to make pregnancy safer. Geneva: World Health Organization; 2004:103-24.

3. Pattinson RC, Buchmann E, Mantel G, Schoon M, Rees H. Can enquiries into severe acute maternal morbidity act as a surrogate maternal death enquiries? Br J Obstet Gynaecol. 2003;110:889-93.

4. Say L, Souza JP, Pattison RC. Maternal near miss towards a standard tool for monitoring quality of maternal health care. Best pract Res Clin Obstet Gynaecol. 2009;23:287-96.

5. Cochet L, Pattinson RC, Macdonald AP. Severe acute maternal morbidity and maternal death audit: a rapid diagnostic tool for evaluating maternal care. S Afr Med J. 2003;93:700-2.

6. Stones W, Lim W, Al-Azzawi F, Kelly M. An investigation of maternal morbidity with identification of life-threatening near miss episodes. Health Trends. 1991;23:13-5.

7. Pattinson RC, Hall M. Near-misses: a useful adjunct to maternal death enquiries. $\mathrm{Br}$ Med Bull. 2003;67:231-43.

8. Say L, Pattison RC, Gulmezoglu AM. WHO systematic review of maternal morbidity and mortality: the prevalence of severe acute maternal morbidity (near miss). Reprod Health. 2004;1:3.

9. Sarma HKD, Sarma HK, Kalita AK. A prospective study of maternal near-miss and maternal mortality cases in FAAMCH, Barpeta; with special reference to its aetiology and management. J Obstet Gynaecol Barpeta. 2014;1(2):100-6.

10. Shrestha J, Shrestha R, Tuladhar R, Gurung S, Shrestha A. Maternal near miss in a tertiary care teaching hospital. American Journal of Public Health Research. 2015;3(5A):17-22.

11. Mustafa R, Hashmi H. Near-miss obstetrical events and maternal death. Journal of the college of physians and surgeons, Pakistan. 2009;19(12):781-5.

12. Roopa PS, Verma S, Rai L, Kumar P, Pai MC, Shetty J. Near miss obstetric events and maternal deaths in a tertiary care hospital: an audit. Journal of Pregnancy. 2013:393758.

13. Almerie Y, Almerie MQ, Matar HE, Shahrour Y, Chamat AA, Abdulsalam A. Obstetric near-miss and maternal mortality in maternity university hospital, Damascus, Syria: a retrospective study. BMC Pregnancy and Childbirth. 2010;10:65.

14. Nelissen EJT, Mduma E, Ersdal HL, Olsen BE, Roosmalen JJM, Stekelenburg J. Maternal near miss and mortality in a rural referral hospital in northern Tanzania: a cross sectional study. BMC. 2013;13:141.

15. Gedefaw M, Gebrehana H, Gizac\$hew A, Taddess F. Assessment of maternal near miss at debre markos referral hospital, Northwest Ethiopia: five years' experience. Open Journal of Epidemiology. 2014;4:199-207. 
16. Wianwiset W. Maternal near miss (severe morbidity) at Sisaket Hospital. Thai Journal of Obstetrics and Gynecology. 2012;20:69-76.

17. Kabakyenga JK, Ostergren PO, Turyakira E, Mukasa $\mathrm{PM}$, Pettersson KO. Individual and health facility factors and the risk for obstructed labor and its adverse outcomes in South-Western Uganda. BMC Pregnancy and Childbirth. 2011;11:73.

18. Trends in Maternal Health in Ethiopia. In-Depth Analysis of the EDHS 2000-2011. UNFPA, Addis Ababa, Ethiopia; 2012.

19. Oladapo OT, Sule-Odu AO, Olatunji AO, Daniel OJ. Near-miss obstetric events and maternal deaths in Sagamu, Nigeria: a retrospective study. Reprod Health. 2005;2:1186-95.

20. Sikeder SS, Labrique AB, Ullah B, Ali H, Rashid M, Mehra S, et al. Accounts of severe acute obstetric complications in rural Bangladesh. BMC Pregnancy and Childbirth. 2011;11:76.

21. Drau PH, Musa J, Achara P, Pam IC. Near miss maternal mortality in Jos University Teaching Hospital (Juth), Jos, Plateau State Nigeria. Ibom Medical Journal. 2008;3:1.
22. Shaheen F, Begum A. Maternal near miss. Journal of Rawalpindi Medical College (JRMC). 2014;18(1):130-2.

23. Pandey M, Mantel GD, Moodley J. Audit of severe acute morbidity in hypertensive pregnancies in a developing country. J Obstet Gynaecol. 2004;24:387-91.

24. Kaye D, Mirembe F, Aziga F, Namulema B. Maternal mortality and associated near-misses among emergency intrapartum obstetric referrals in Mulago Hospital, Kampala, Uganda. East Afr Med J. 2003;80:144-9.

25. Fillipi V, Ronsmans C, Gohou V, Goufodji S, Lardi M, Sahel A, et al. Maternity wards or emergency obstetric rooms? Incidence of near- miss events in African Hospitals. Acta Obstet Gynaecol Scand. 2005;84:11-6.

26. Shrestha NS, Saha R, KArki C. Near miss maternal morbidity and maternal mortality in Kathmandu Medical College Teaching Hospital. Kathmandu. Univ Med J (KUMJ). 2010;8(2):222-6.

27. Rana A, Baral G, Dangal G. Maternal near miss: a multicentric surveillance in Kathmandu valley. J Nepal Med Assoc. 2013;52(190):299-304.

Cite this article as: Yasmin G, Najam R, Ghazi S, Lalwani A. Maternal near miss events: a prospective observational study in a tertiary care centre. Int J Reprod Contracept Obstet Gynecol 2016;5:3088-93. 